\title{
As Idéias Psicopedagógicas e a Espiritualidade no Karate-Do segundo a Obra de Gichin Funakoshi
}

\author{
Cristiano Roque Antunes Barreira ${ }^{1}$ \\ Marina Massimi \\ Universidade de São Paulo, São Paulo
}

\begin{abstract}
Resumo
O karate é uma forma de luta com origens remotas, pouco conhecidas e marcado desenvolvimento na ilha de Okinawa do arquipélago japonês. Outrora praticado às escondidas, no século XX Gichin Funakoshi tornou-o público e o difundiu. Partiu de Funakoshi a denominação karate-do, "o caminho das mãos vazias", que dá um caráter doutrinário à arte que deveria servir, mais do que como mera forma de luta, ao desenvolvimento da personalidade. Procura-se fazer um resgate teórico das idéias psicopedagógicas e da espiritualidade próprias do karate sob a luz dos paradigmas culturais de maior influência no pensamento de Funakoshi. Observa-se claramente a influência e complementaridade entre confucionismo e zen-budismo além da herança prática do bushidô que permitem compreender o pensamento de Funakoshi acerca da espiritualidade e transmissão do conhecimento. Palavras-chave: Karate; idéias psicológicas e psicopedagógicas; esportes de combate; espiritualidade.
\end{abstract}

The Karate-Do Psychopedagogic Ideas and Spirituality According to Gichin Funakoshi's Work

\begin{abstract}
Karate is a fight practice whose beginnings are unknown, but which developed highly in Okinawa, an island of the Nipponic archipelago. In early times, karate used to be a secret practice. It became a public practice in the twentieth-century, by the practice of Gichin Funakoshi, who named it karate-do, or 'the way of empty hands". In doing so, he gave a doctrinal character to the art of karate, so that it could serve to develop a sense of personality and not just a way of fighting. In this study, we present a theoretical survey of the psychopedagogical ideas and spirituality of karate through the perspective of the cultural paradigms contained in Funakoshi's thought. The influence and complement of Confucian philosophy and Zen-Buddhism, in addition to the practice influenced by bushido, was made evident. This allows us to understand Funakoshi's thought regarding psychopedagogical ideas and spirituality.

Keywords: Karate; psychological ideas; combat sports; spirituality.
\end{abstract}

A expansão do karate pelo mundo ocorreu rápida e entusiasticamente século XX afora. Os gérmens dessa expansão são devidos a Gichin Funakoshi que após leválo da ilha de Okinawa ao Japão foi, por todo o trabalho realizado em vida e continuado por seus discípulos, tido como o fundador do karate moderno. Em seus livros sustentou que essa forma de combate sem armas, praticada por militares e, sobretudo, civis, antes de incitar à violência seria, se adequadamente ensinada, uma arte para a educação e aperfeiçoamento da personalidade do praticante. Talvez a transmissão dessas idéias, na mesma linha educacional proposta por Jigoro $\mathrm{Kano}^{2}$, tenha sido responsável pelo respeito com que o karate ainda hoje é visto.

\footnotetext{
${ }^{1}$ Endereço para correspondência: Rua Faveiro, 35, 14040 130, Ribeirão Preto, SP. Fone: (16) 6308356.E-mail: crisroba@usp.br; mmarina@ffclrp.usp.br ${ }^{2} \mathrm{O}$ mestre que criou o Judô 'lapidando' o jiu-jitsu, que era usado como técnica para brigas de rua.
}

Nascido em Okinawa em1868 e morto em Tóquio, ilha central do arquipélago japonês, em 1957, a vida de Gichin Funakoshi pode ser resumida em termos de seus esforços pela divulgação de sua arte e pelo reconhecimento desta como método educacional. Provindo de família com parcos recursos econômicos e fortemente apegada às tradições locais, tornou-se professor primário em 1888 graças ao aprendizado dos clássicos chineses dado sob supervisão de seu avô materno e de seu professor de karate, Yasutsune Azato. Na década de 1920, após liderar uma demonstração de karate diante do Imperador, o interesse do público nipônico pela misteriosa forma de luta floresceu intensamente e Funakoshi acabou por se estabelecer em Tóquio. Seguiu aquela década ensinando para poucos alunos e sustentando-se com dificuldades, trabalhando, inclusive, como zelador em um pensionato para estudantes. No final dos anos 1920, começava a ensinar em Universidades e os anos 1930 presenciaram os que são chamados os anos de ouro do karate. $\mathrm{O}$ aumento do número de praticantes, sobretudo de jovens, reforçou sua ênfase sobre o aspecto educacional, conforme o enfoque examinado neste trabalho. A guerra 
contra a China e, finalmente, a Segunda Grande Guerra tiveram sua influência sobre o karate, mormente a última, após a qual o número de praticantes caiu drasticamente. $\mathrm{O}$ retorno do crescimento deu-se sob um novo espírito, marcado pelo belicismo e pouco acompanhado por Funakoshi que permaneceu, no entanto, como personagem reverenciado. Em seus últimos anos ensinava para pouquíssimos alunos, isso devido à sua idade avançada e métodos então tidos como antiquados, fatores que não atraíam praticantes. Funakoshi pouco viu da explosão internacional abrangida pelo karate. Apesar do novo espírito perpretado pelo karate pós-guerra, a foto de Funakoshi é exposta maciçamente nas paredes das academias de karate mundo afora que, mesmo sem conhecer profundamente sua história e suas idéias, reverenciam-no como o pai do karate.

O pensamento de Funakoshi, inclusive suas idéias psicológicas, foi transmitido inicialmente no contato com seus alunos que, por suas vezes, cuidaram para manter vivo e retransmitir o que Funakoshi considerava a essência do karate. Pode-se pensar que hoje, mais de quatro décadas após sua morte, sua obra escrita esteja contribuindo para a perpetuação de seu pensamento. Se o tempo distancia seu pensamento de nós, as diferenças culturais de suas origens o afastam ainda mais, não só no âmbito dos países ocidentais mas também no próprio Japão que há tempos passa por intensas transformações internas.

O contexto de origem do karate e de outras formas de combate no Japão feudal era extremamente influenciado por uma mentalidade religiosa que sustentava desde a moralidade e leis, até a estratificação e hierarquia social. Essa mentalidade provinha, sobretudo, do xintoísmo, a religião nativa do Japão, do confucionismo e do budismo - esse último, no caso das artes, essencialmente em sua forma zen.

O passar do tempo e a distância cultural têm contribuído para a incompreensão e perda das idéias psicológicas contidas no pensamento de Funakoshi. Nesse processo, suas concepções acerca de atitude e de moralidade, por serem normalmente ligadas mais à ação e comportamento, sofrem desgastes menos intensos do que as idéias que correspondem a um pensamento psicopedagógico e a uma espiritualidade próprias da prática do karate-do.

O objetivo dessa pesquisa é localizar e compreender, conforme os parâmetros que as originaram, as idéias psicológicas, referentes especificamente ao pensamento psicopedagógico e à espiritualidade, contidas na obra escrita de Gichin Funakoshi. O resgate das idéias psicológicas, que fazem com que o karate sirva ao aprimoramento do caráter e personalidade, pretende contribuir para que não se perca o que é tido por Funakoshi como a essência do karate não sua técnica, mas suas contribuições à formação do homem.
Utilizando-se de métodos próprios da historiografia das idéias psicológicas (Massimi, 1998; Massimi, Campos \& Brozek, 1996), esta pesquisa trata de contextualizar a origem de tais idéias procurando compreender o karate em seu universo sócio-cultural. De acordo com esse método a ênfase sobre o conteúdo examinado é seguido do reconhecimento de aspectos que o influenciou e o originou, na busca por uma compreensão de seu sentido. Assim, o conteúdo examinado é aquele reconhecido como sendo as idéias psicopedagógicas no karate a partir da obra de Gichin Funakoshi. A análise desse pensamento é realizada através dos referenciais paradigmáticos que, entende-se, devem ter exercido grande influência em sua produção e desenvolvimento. Os documentos escolhidos para esse fim foram produzidos antes ou durante o período de vida de Gichin Funakoshi ${ }^{3}$. O motivo de escolha dos documentos nessa periodização, é que ela abrange tanto potenciais influências diretas sobre o autor, como também produções contemporâneas a ele, o que encerra o risco de anacronismos históricos e garantem, pela temática, uma leitura devidamente fundamentada.

Abaixo o texto divide-se em duas partes intituladas Aprender com o Corpo e A Arte do Vazio, seguidos de uma conclusão.

\section{Aprender com o Corpo}

Funakoshi afirma que:

o karate-do não pode ser assimilado pelos olhos e pelos ouvidos; ele precisa ser vivido e compreendido através do treinamento físico. Por isso, mesmo se você se dedicar somente ao ten no Kata ${ }^{4}$ e o praticar com todo o coração até dominá-lo, posso assegurar, sem nenhuma reserva, que você chegará a compreender o verdadeiro significado do karate-do. (Funakoshi, 1998, p. 12)

Diversos fatores poderiam ter originado a idéia exposta acima. Sem dúvida alguma, a principal fonte deve ter sido a própria experiência de Funakoshi. Todavia, reconhecese que também refletem algumas das influências culturais por ele recebidas. Uma delas é o confucionismo, que "recusa a tudo o que seja abstrato e apenas teórico" (Doeblin, 1940, p. 16). O conhecimento depende de algo além do pensamento racional, principalmente quando tem

\footnotetext{
${ }^{3}$ listam-se livros de Funakoshi que são examinados e os que são utilizados como referênciais teóricos: Funakoshi (1975/1994, 1988, 1973/1997), Sasaki (1995), Suzuki (1969/1992), Doeblin (1940), Herrigel (1975/1995), Musashi (1984/1996) e Tzu (1983/1997).

${ }^{4}$ ten no kata é uma prática de exercícios de técnicas simples do karate.
} 
uma aplicação física: "Ensine a estratégia ao seu corpo" (Musashi, 1996, p. 73) escreveu o samurai Miyamoto Musashi que tem, em seu 'Go Rin No Sho' ('O livro de cinco anéis'), um dos documentos mais representativos do bushidô ('caminho do guerreiro', espécie de ideologia dos samurais desde o Japão feudal). Já no Zen, minimizase o valor das idéias por si mesmas, das idéias que não estejam ligadas à prática, por isso elas devem estar 'no corpo': "As idéias abstratas que não se reflitam na vida prática são consideradas sem valor. A convicção tem que ser ganha através da experiência e não através de abstrações" (Suzuki, 1992, p. 144). A experiência de Eugen Herrigel como aprendiz do Zen, fez-lhe perceber que sua busca por algo místico também não poderia ficar no âmbito do pensamento verbal:

Eu compreendera que não havia outro caminho que conduzisse ao misticismo, a não ser o da própria vivência e do sofrimento. Se faltam essas premissas, fica apenas o inconseqüente palavrório. (Herrigel, 1995, p. 26)

Reforçando a idéia de que a aprendizagem depende muito mais da experiência, da vivência, do próprio sofrimento, o pensamento de Funakoshi fica ainda mais claro e direto neste recorte.

Você não pode treinar por meio de palavras. Você precisa aprender com o corpo. Para suportar a dor e a aflição enquanto se esforça para se disciplinar e polir, você precisa acreditar que, se os outros podem, você também pode. Pergunte-se, "O que está me detendo? O que estou fazendo errado? Está faltando alguma coisa no meu modo de ver a situação?’ Isso é treinamento nas artes marciais.

Aspectos importantes que outras pessoas nos ensinaram podem ser esquecidos rapidamente, mas a essência do conhecimento adquirido com dificuldade e sofrimento jamais será esquecida. (Funakoshi, 1998, p. 48)

Esse texto aproxima-se do pensamento de Musashi, escrito séculos antes:

A palavra não consegue explicar o Caminho com todos os seus detalhes, mas ele pode ser apreendido intuitivamente. ... Apenas lendo esse livro você não atingirá o Caminho da Estratégia. Absorva o que vai escrito aqui. Não se limite a ler, memorizar ou imitar, mas, para penetrar no princípio e tê-lo gravado em seu coração, estude, estude muito. (Musashi, 1996, p. 55)

Você pode aprender como vencer através da estratégia da espada longa, mas isso não pode ser explicado apenas por escrito. Será preciso praticar muito a fim de saber como vencer. Tradição oral: "O verdadeiro Caminho da Estratégia é revelado na espada longa”. (Musashi, 1996, p. 72).
Nesses textos a ênfase está na prática como maneira real de se aprender, sugerindo que a aprendizagem não seja algo que venha de fora para dentro, mas deva ser estimulada, possa ser facilitada, provenha do interior de si próprio, só assim se tornará uma experiência real: "A menos que brote de ti mesmo, nenhum conhecimento é realmente teu. É apenas uma plumagem emprestada" (Suzuki, 1992, p. 117). A transmissão do conhecimento verdadeiro, de um para o outro, dependeria então de uma espécie de "maturação" interna daquele que aprende. $O$ mestre ensina a partir do que é experienciado pelo seu aprendiz: "O mestre pode mostrar-lhe algo de que tinha ouvido falar muitas vezes, mas cuja realidade só agora fica tangível, em virtude de suas próprias experiências" (Herrigel, 1995, p. 56).

Considera-se também que a aprendizagem ocorre verdadeiramente através da dificuldade. Isto teria seus resultados refletidos na vida diária ocasionando a 'força mental', ou persistência, necessária para superar obstáculos ao longo da vida:

... pense na vida de cada dia como um treinamento em karate. Não limite o karate apenas ao dojo, nem o considere apenas um método de luta. O espírito da prática do karate e os elementos do treinamento se aplicam a todos e a cada um dos aspectos da nossa vida diária. $\mathrm{O}$ espírito nascido do esforço e do ranger os dentes de frio no treinamento durante o inverno, ou nascido do suor no treinamento do verão, pode ser-lhe muito útil em seu trabalho. E o corpo que se forjou nos chutes e socos da prática intensa não sucumbirá às provocações de estudar para um exame difícil, ou de levar a cabo uma tarefa enfadonha. Alguém cujo espírito e força mental, se fortaleceram através das lutas com uma atitude de nunca desanimar não deve encontrar dificuldade em enfrentar nenhum desafio, por maior que ele seja. (Funakoshi, 1998, p. 51)

Outro trecho de Funakoshi é significativo desta mesma atitude:

Você descobrirá que o treinamento, feito com uma atitude implacável e fatal, com o tempo irá beneficiar não somente o seu estudo do karate, mas também muitos outros aspectos de sua vida. A vida em si muitas vezes se assemelha a uma competição com espadas reais. Com uma atitude tíbia para com a vida - como supor que depois de cada fracasso você terá sempre uma segunda oportunidade - o que você espera realizar num curto período de cinqüenta anos? (Funakoshi, 1998, p. 47)

Além de apontar a necessidade de treinar com intensa seriedade - não se limitando a praticar os exercícios físicos do karate, mas de praticá-los com sua dimensão psicológica indispensável - há mais uma vez a relação da 
prática com a vida. Compara-se diretamente a luta com a vida, a necessidade de se passar em ambas as situações, de luta e de vida, sem deixar escaparem as oportunidades, pois isso pode significar a derrota e a não realização de seus potenciais de vida. A atitude para ambas deve ser a mesma, como diz também o samurai Miyamoto Musashi: "A essência desse livro é a de que o guerreiro tem que treinar dia e noite a fim de tomar decisões rápidas. $\mathrm{Na}$ estratégia, é importante tratar o treinamento como parte da vida normal, sem qualquer mudança de espírito" (Musashi, 1996, p. 45).

A persistência, o tempo, o treinamento, enfim um longo processo - "O karate precisa ser criado e aperfeiçoado" (Funakoshi, 1998, p. 54) - é necessário para o aprendizado nas artes marciais e na vida: "Passo a passo, atravessa-se uma estrada de mil quilômetros. Estude a estratégia, ano após ano, e adquira o espírito do guerreiro" (Musashi, 1996, p. 73).

Um dos conceitos mais importantes para o treinamento é o seguinte: "Se você compreende realmente uma única técnica, você só precisa observar as formas e receber informações sobre os pontos essenciais das outras. Então, você terá condições de assimilá-las em tempo relativamente curto" (Funakoshi, 1998, p. 49).

Sobretudo entre os principiantes há a idéia de que a quantidade de kata (exercícios práticos individuais que simulam uma luta), por exemplo, mede o conhecimento do carateca. Substitui-se a qualidade pela quantidade e há uma busca pelo rápido aprendizado de vários kata. Como já visto porém, a idéia de aprendizado no karate, não está vinculada somente a memorização, mas a uma longa experiência, à vivência prática. Funakoshi conta que em 10 anos de treinamento com mestre Itosu aprendeu três kata (a série Tekki), passando mais de 3 anos no aprendizado de cada um, embora memorizá-los não levasse mais do que 20 ou 30 minutos. Nesse sentido, considera-se que o verdadeiro aprendizado depende da compreensão real da técnica.

O estrategista transforma coisas pequenas em grandes coisas, como a construção de um grande Buda a partir de um modelo de trinta centímetros. Não posso escrever detalhadamente sobre como isso é conseguido. O princípio da estratégia é, tendo-se uma coisa, conhecerem-se dez mil coisas. (Musashi, 1996, pp. 44-45)

Aproximam-se muito os conceitos de aprendizagem que parecem estar ligados às longas experiências de vida dos praticantes de artes marciais. A semelhança do pensamento provém, dentre outras coisas, da maneira de ensino dessas artes no Japão entre os samurais. "De uma coisa aprenda mil coisas” (Musashi, 1996, p. 48). O aprendizado aprofundado, real, de uma técnica para o karate, identifica-se com o aprendizado aprofundado de uma arte para a vida: "Quando se atinge o Caminho da Estratégia, não haverá mais nada que não se possa compreender" e "se verá o caminho em tudo" (Musashi, 1996, p. 29). Portanto, o conceito remete à necessidade da dedicação sincera e aprofundada a uma única coisa, que então servirá de guia a todas as outras.

Mestre Azato transmite a Funakoshi um costume realmente antigo, cujas raízes perdem-se aquém do confucionismo:

Pelo que sei, fui o único discípulo de Mestre Azato, de vez que ele confiou o treinamento do seu filho mais velho a Itosu. Uma vez ele me disse: 'Desde os tempo antigos, as pessoas perceberam a dificuldade de ser professor dos próprios filhos, e por isso era prática comum confiarem a educação dos mesmos a terceiros. Eu lhe ensinarei muitas coisas sobre karate; por favor, ensine o que você aprender, e do modo como aprender, a meu filho.' (Funakoshi, 1998, p. 33)

Um dos principais estudos de Confúcio e do confucionismo refere-se à história, tradições, costumes e rituais antigos, como forma de compreensão daquilo que mantém a harmonia nas comunidades. Sabendo-se que mestre Azato fora um estudioso do confucionismo, podese supor que essa tenha sido uma das fontes de sua atitude de encaminhar o filho ao amigo, Mestre Itosu. No trecho seguinte há o motivo de tal cuidado:

Kung-sun Ch'âu disse: Por que o homem superior não ensina por si mesmo ao seu filho?

Mêncio replicou: As circunstâncias impedem que ele assim proceda. O mestre deve ensinar o que é correto. Quando ensina o que é correto e suas lições não são praticadas, leva-as adiante com cólera. Quando as leva adiante com cólera, contra o que devera ocorrer, ofende-se com seu filho.

Os antigos trocavam seus filhos e um ensinava ao filho do outro.

Entre pai e filho não deve haver reprovações e conselhos para o bem. Semelhantes censuras levam à desunião e nada é mais desfavorável do que a desunião. (Doeblin, 1940, p. 140)

Nesse trecho, Funakoshi escreve sobre sua profunda crença de que o karate, quando ensinado com adequada orientação, segundo os princípios e valores morais e éticos do budô, é uma arte que, longe de trazer riscos, só teria a contribuir, sendo usada somente quando necessária.

Esta arte marcial, quando corretamente compreendida, ensinada e praticada dentro do seu verdadeiro espírito, é a antítese do perigo e uma das mais nobres artes marciais (Budô). Drogas fortes e venenos também são perigosos, no 
entanto, nenhum médico deixa de usá-los, quando é necessário. O perigo depende do uso que se faz: quando devidamente usados, podem trazer resultados valiosos, desde que o paciente seja informado de sua natureza e uso adequado. Do mesmo modo, os que aprendem karate-do devem conhecer sua natureza e serem instruídos no uso adequado de suas técnicas. O entendimento correto da natureza do karate e o uso adequado de suas técnicas é o karate-do. (Funakoshi, citado em Sasaki, 1995, p. 90)

Portanto a compreensão daquilo que envolve o karate, não só tecnicamente como difundido mundo afora, mas principalmente em termos de sua moralidade e valores, seria fundamental para que não se perca de vista aquilo que objetivava o difusor do karate.

Duas idéias centrais ainda devem ser desenvolvidas. A primeira é a de que o carateca não é tal apenas no momento do treino, mas permanece carateca em todos os momentos de sua vida, o que implica em que sua atitude não deva mudar nem publicamente, nem intimamente: “...viver karatedo é a própria vida, tanto pública como pessoal" (Funakoshi, citado em Sasaki, 1995, p. 92); “ ... viva sua vida de acordo com a ética, quer em público quer em particular. Este é um princípio que exige a observância mais rígida" (Funakoshi, 1994, p. 116).

A segunda é a de que a relação entre professor e aluno se estende além da instrução técnica.

Alguns jovens acreditam que o karate possa ser aprendido somente de instrutores num dojo, mas estes são simples técnicos, não caratecas verdadeiros. Há um ditado budista que diz que qualquer lugar pode ser um dojo, esse é um ditado que nenhuma pessoa que queira seguir o caminho do karate deve esquecer. O karate-do não é somente a aquisição de certas habilidades defensivas, mas também o domínio da arte de ser um membro da sociedade bom e honesto. (Funakoshi, 1994, pp. 109-110)

Conforme o ditado budista que cita, temos um pouco sobre a relação mestre/discípulo no budismo:

Desde tempos imemoriais, a relação entre mestre e discípulo pertence às relações elementares da vida e ultrapassa muito os limites da matéria que ensina. No princípio, a única coisa que se lhe exige é que imite respeitosamente tudo o que o mestre faz. Pouco amigo de prolixos doutrinamentos e motivações, ele se limita a breves indicações e não espera que o aluno faça perguntas. Observa tranqüilamente suas ações, sem esperar independência ou iniciativa própria, aguardando com paciência o crescimento e a maturação. Os dois dispõem de tempo: o mestre não pressiona, o discípulo não se precipita. (Herrigel, 1995, p. 51)
A arte é estimulada a surgir no homem através da técnica que, em si, ainda não é arte: "A técnica é transformada em arte por quem a emprega" (Funakoshi, citado em Sasaki, 1995, p. 91). Toda a concepção de aprendizagem, acima destacada, faz parte da maneira pela qual pode-se fazer de uma técnica uma arte através do homem. Todo o processo, a dificuldade, o empenho a uma área estrita, a dedicação intensa, física e psíquica, o método de transmissão, fazem parte da transformação, pelo homem, da técnica em arte.

Longe de querer despertar prematuramente o artista, o mestre considera como sua missão primordial converter o discípulo num artesão que domine profundamente o ofício, o que este fará com a sua habitual e pertinaz dedicação e como se não tivesse aspirações mais elevadas, submetendo-se ao duro aprendizado com resignação, para descobrir, com o passar dos anos, que o domínio perfeito da arte, longe de oprimir, libera. (Herrigel, 1995, p. 51)

... a criação autêntica só é possível num estado de desprendimento de si mesmo, durante o qual o criador não está presente como ele mesmo. (Herrigel, 1995, p. 55)

... se a graça lhe é reservada, o discípulo descobre em si mesmo que a obra interior que ele deve realizar é bem mais importante que as obras exteriores, por mais atraentes que sejam, e que ele deve persegui-la, se quiser ser o artífice do seu destino de artista.

A obra interior consiste em que o aluno, como homem que é, como o eu que se sente ser e como homem que se reencontra uma ou outra vez, se converta na matéria-prima de uma criação, de uma realização formal, que termina no domínio da arte escolhida. (Herrigel, 1995, p. 56)

\section{A Arte do Vazio}

Poetas do mundo todo cantaram suas canções sobre os mistérios da meditação que permeia os bosques e florestas, e eu era atraído pela solidão fascinante de que são símbolo. Talvez meu amor pela natureza fosse intensificado pelo fato de eu ser filho único e criança frágil, mas seria exagero de minha parte considerar-me um "solitário". Apesar disso, depois de uma prática intensa de karate, não tinha coisa melhor do que sair e perambular sozinho. (Funakoshi, 1994, pp. 95-96)

Por aquela época eu já praticava karate há alguns anos, e à medida que aprofundava meu conhecimento da arte tornava-me mais consciente de sua natureza espiritual. Usufruir minha solidão enquanto ouvia o vento assobiando por entre os pinheiros era, me parecia, um modo excelente de alcançar a serenidade que $\mathrm{o}$ karate exige. (Funakoshi, 1994, p. 96)

A passagem acima é um relato acerca de sua tomada de consciência dos elementos tidos por Funakoshi como a 
verdadeira essência de sua arte. Foi também esse contato com a floresta de pinheiros que o inspirou a assinar seus poemas com o pseudônimo Shoto ("ondas de pinheiros"), que posteriormente deu o nome à sua escola de karate, a Shotokan (escola do Shoto). Nos quatro quilômetros de caminhada entre sua casa e a de seu mestre, percorridos diariamente durante a madrugada em uma época na qual o karate ainda era praticado sob sigilo, sua experiência com a arte parece ter-se enriquecido. Essa experiência foi fundamental para sua percepção acerca da espiritualidade na arte. Tais palavras, entretanto, não permitem que se tenha uma medida da importância que a 'meditação', realizada nesses momentos, tenha tido em sua vida. Para o zen o efeito da meditação não é algo a ser transmitido, pode ser experienciado:

... cheguei à conclusão de que só quem verdadeiramente se isola é capaz de aprender o que significa isolamento, e só quem leva uma vida contemplativa está completamente livre e desprendido de si para a união com o 'Deus supradivino'. (Herrigel, 1995, p. 26)

Fica claro, contudo, que essa experiência tenha certamente contribuído para o fortalecimento dos valores morais, éticos e espirituais transmitidos junto ao ensino das técnicas, que faria com que o desenvolvimento pessoal ficasse ligado ao conjunto físico e mental. Os alunos das universidades da época estudavam karate, a

maioria deles, felizmente, com o objetivo duplo de fortalecer seu vigor espiritual e sua força física ... Somente os que têm um ideal superior acharão o Karate-do interessante o bastante para perseverar nos rigores que ele requer. Os que persistirem descobrirão que quanto mais treinarem, mais fascinados ficarão pela arte. (Funakoshi, 1994, p. 112)

A necessidade de um ideal de desenvolvimento é ressaltada, pois Funakoshi entende que os valores do karate permaneçam para toda a vida e para o homem como um todo (físico, espiritual e moral), não apenas correspondendo a uma prática física:

Pode-se ter como meta o desenvolvimento da força muscular dos braços e das pernas ou ainda o equilíbrio e a firmeza da mente. Há quem deseje aprender a humildade através do karate. Todos esses objetivos estão relacionados com o desenvolvimento pessoal. (Funakoshi, citado em Sasaki, 1995, p. 91)

Funakoshi acrescentou à denominação karate a palavra do, querendo enfatizar o caráter de 'doutrina' intrínseco à arte. Mais do que isso, deixa transparecer estar ciente de que as características técnicas do karate iriam evoluir e se modificar com o passar do tempo, porém algo de profundo, sua natureza, deveria permanecer.

Do, que significa um "caminho" ou "via" para o aprimoramento pessoal, tem vida própria, quer seja o do de budo, "artes marciais", ou o do das várias outras artes. Precisamente por ter vida própria é que está sujeito ao ciclo inevitável de desenvolvimento e declínio. Ele está sempre mudando, mas só em sua forma exterior; sua natureza fundamental permanece imutável. Se o caminho atrai uma pessoa para percorrê-lo, ele floresce; caso contrário, ele definha. O caminho do karate pode ser chamado com justiça de um budo que se manifesta de forma nova e que busca zelosamente pessoas que por ele sigam. (Funakoshi, 1998, pp. 11-12)

Apesar então das novas manifestações formais, que Funakoshi sabia serem inevitáveis, a busca pelo desenvolvimento deveria permanecer para sempre. Sua concepção de desenvolvimento é a do budismo, acreditando que isso dependeria de uma nova forma de se colocar e se dirigir no mundo. Segundo essa concepção há uma pureza fundamental que é expressa pela 'vacuidade' e não é de fácil compreensão. Provém da experiência e meditação, acumuladas com o tempo até o momento em que se atinge o sator:

Essa intuição reconhece, sem nenhuma espécie de meditação, que o zero é o infinito e que o infinito é o zero. E isso não constitui uma indicação simbólica ou matemática, mas uma experiência diretamente apreensível, resultante de uma experiência direta. Psicologicamente falando, o satori consiste numa transcendência dos limites do ego. (Suzuki, citado em Herrigel, 1995 , pp. 10-11)

No treinamento marcial o esforço intenso é necessário porque "só assim conseguirá dar polimento em sua habilidade, tornar-se liberta do eu e alcançar uma perícia extraordinária. Seu poder será miraculoso" (Musashi, 1996, p. 76). Portanto, esse sentido de desenvolvimento parte de um princípio de desprendimento de aspectos que são entendidos como empecilhos ao crescimento espiritual:

... os estudantes de karate-do têm como meta não só aperfeiçoar a arte de sua escolha mas também esvaziar o coração e a mente de todo desejo e vaidade terrenos. Lendo as escrituras budistas, encontramos afirmações como "Shiki-soku-zeku" e "Ku-soku-zeshiku", que literalmente significam "matéria é vazio" e "tudo é vaidade". O caractere $k u$, que aparece nas duas admoestações e que pode também ser pronunciado kara, é em si mesmo verdade.

Assim, embora as artes marciais sejam muitas ..., o objetivo de todas elas é o mesmo que o do karate. Acreditando com 
os budistas que é a vacuidade, o vazio, que jaz no coração de toda matéria e na verdade de toda a criação... (Funakoshi, 1994, p. 47)

O que fica como de natureza fundamental são, portanto, suas atribuições éticas, morais e espirituais. As atribuições espirituais advêm de conceitos budistas e estão carregadas de valores morais, ficando dificultada a separação desses conceitos. No zen-budismo, considera-se que a moralidade é decorrência direta do desenvolvimento espiritual não merecendo portanto uma atenção específica, por isso a integração desses elementos sempre é dada. Também a difícil descrição dos resultados espirituais do zen-budismo faz entender porque, comumente, são eles explicados através de atribuições morais. Tecnicamente, Eugen Herrigel $^{5}$ cita um trecho de um mestre de zen, Takuan, para explicar como é esse vazio através da esgrima: Assim, tudo é um vazio: você mesmo, a espada que é brandida e os braços que a manejam. Até a idéia de vazio desaparece. Desse vazio absoluto desabrocha, maravilhosamente, o ato puro (Herrigel, 1995, pp. 85-86).

No zen-budismo, tem-se ainda que a transcendência da consciência, inclusive da consciência moral que dita o puro e o impuro, é necessária para se atingir a pureza. Suzuki cita o Mestre Zen Vimalakirti:

Quando a mente está absolutamente pura, tendes uma mente purificada, e diz-se que a mente está absolutamente pura quando se acha acima da pureza e da impureza. Desejais saber como isso é conseguido? Esvaziai a mente de todas as condições e então tereis a pureza. Quando isto for alcançado não acolhais pensamento a respeito, ou voltareis à impureza. Ao atingirdes o estado impuro não abrigais nenhum pensamento a seu respeito e então estareis livre da impureza. Esta é a pureza absoluta. (Suzuki, 1992, p. 78)

No karate o esvaziamento da mente de todas as condições significa conhecê-las tão profundamente que o ato que condiciona uma resposta é feito sem a recorrência ao pensamento consciente. É o ato puro que exige uma longa jornada de treinamento sem intervalo, para ocorrer a superação do ato consciente. Esse seria o vazio que é, ao mesmo tempo, tudo. Funakoshi usa no trecho abaixo uma metáfora para transmitir a pureza do ato.

Assim como um vale vazio pode ecoar o som da voz, do mesmo modo a pessoa que segue o Caminho do Karate deve esvaziar-se livrando-se de todo egoísmo e ambição. Tornar-

\footnotetext{
${ }^{5} \mathrm{O}$ alemão Eugen Herrigel é autor do popularizado livro "A arte cavalheiresca do arqueiro Zen", tendo estudado o zen-budismo no período em que lecionou filosofia no Japão.
}

se vazio interiormente mas reto por fora. Este é o significado verdadeiro de "vazio" no karate.

Quando a pessoa percebe a infinidade de formas e de elementos no universo, ele se volta para o vazio, para o vácuo. Em outras palavras, o vazio não é outra coisa senão a verdadeira forma do universo. (Funakoshi, 1998, p. 26)

A percepção da infinidade de formas e elementos do universo corresponderia, na luta, à percepção da infinidade de gestos e possibilidades, estes, após assimilados, podem ter uma resposta "pura", "vazia", sem a necessidade do pensamento. Assimilado o universo, ele assim também se torna "vazio" e esta é a "forma do universo", a realidade mais pura.

A segunda conotação do símbolo kara é: como o espelho límpido que reflete a imagem sem distorção ou o vale tranqüilo que repete o som, assim também deve o praticante do karate purificar-se do egoísmo e dos maus pensamentos, pois só uma mente pura pode compreender, sem distorção, o que recebe. (Funakoshi, citado em Sasaki, 1995, p. 88)

A atribuição moral ressurge aqui indicando empecilhos mentais à percepção pura da realidade. O egoísmo e os maus pensamentos são como nódoas no espelho que o impedem de refletir a realidade. No zen, propriamente, não há essa atribuição moral quanto ao egoísmo ou maus pensamentos. Há, sim, um maior radicalismo em relação ao próprio raciocínio intelectual, que é tido como escravizante:

Equivale a reconhecer os fatos como fatos e saber que palavras são palavras e nada mais. $\mathrm{O}$ zen, não raro, compara a mente a um espelho livre de manchas. Ser simples, portanto, de acordo com o Zen, significa manter este espelho sempre brilhante e limpo, pronto a refletir, pura e simplesmente, o que dele se acercar. (Suzuki, 1992, p. 83)

Esse é mais um argumento contra a realização do karate à mercê da técnica, isto é, de um karate teórico.

A seguir, temos recortes de trechos nos quais Funakoshi conta, em dois momentos diferentes, uma mesma história acerca de um lendário combate resolvido sem troca de golpes. Os textos abordam as lições tiradas por um dos protagonistas sobre a situação vivida. Apenas os comentários referentes à conclusão essencial serão aqui transcritos. Eles teriam sido feitos por Matsumura Sensei que, desafiado por Uehara, teria vencido o combate sem golpeá-lo:

Hoje sou um homem mais sábio do que ontem. Sou um ser humano, e um ser humano é uma criatura vulnerável, que possivelmente não pode ser perfeita. Depois da morte, retorna aos elementos -à terra, à água, ao fogo, ao vento, ao 
ar. Matéria é vazio. Tudo é vaidade. Somos como folhas de grama ou como árvores da floresta, criação do universo não tem vida nem morte. A vaidade é o único obstáculo à vida. (Funakoshi, 1994, p. 41)

... Em essência, um homem é apenas uma agregação temporária dos Cinco Princípios e dos Cinco Elementos. Quando o seu tempo chega ao fim essa forma se desintegra rapidamente, voltando a ser os elementos terra, água, fogo, vento e ar. Quando o homem se dá conta da evanescência de todas as coisas, é fácil ver que não há uma entidade como o eu e, conseqüentemente, também não existe algo como o outro. Os seres humanos, como a relva ou as árvores, ou como tudo na natureza, são apenas agregados físicos do espírito que permeia todo o universo. Para o espírito do universo, os conceitos de vida e de morte não tem sentido. Quando se está livre dos apegos, não há obstáculos nem empecilhos. (Funakoshi, 1998, pp. 129130)

Há uma idéia de desenvolvimento humano nessa concepção de vida e morte. Essa idéia faz parte da cultura do zen e do bushidô:

O significado da vida e da morte pela espada se refletia na conduta habitual da sociedade feudal japonesa; todo aquele que atingisse a aceitação resoluta da morte, a qualquer momento de sua vida, seria considerado um mestre da espada. (Musashi, 1996, p. 17)

A aceitação resoluta da morte teria a força de superar o 'aprisionamento' do homem aos apegos ou aos sentimentos.

Através de longos anos dedicados à meditação ele descobriu que, no fundo, a vida e a morte são uma única coisa, e que ambas pertencem ao mesmo plano do destino. Ele não sente a angústia de viver, nem o temor da morte. (Herrigel, 1995, p. 88)

Esse seria o auge do desenvolvimento humano, o alcance do máximo dentro do budô, e significaria o alcance pleno dos potenciais humanos, pois quaisquer outros valores seriam pequenos quando defrontados com a morte.

Muitas vezes digo a meus alunos uma coisa que acham confusa. Digo-lhes: 'Vocês devem tornar-se fracos, não fortes.' Logo querem saber o que quero dizer com isso, pois uma das razões que os levaram a escolher o Karate-do é a possibilidade de se tornarem fortes. Não há necessidade de treinamento para se tornar fraco, dizem eles. Respondo então que o que estou dizendo é de fato difícil de compreender 'Quero que encontrem a resposta dentro de vocês mesmos', digo-lhes. 'E prometolhes que vai chegar o momento em que vão compreender realmente o que quero dizer'.
... Aquele que está consciente de suas próprias fraquezas será senhor de si mesmo em qualquer situação. Somente uma pessoa verdadeiramente fraca é capaz de coragem verdadeira. Naturalmente, um praticante verdadeiro deve aperfeiçoar suas técnicas através do treinamento, mas nunca deve esquecer que somente através do treinamento será capaz de reconhecer suas próprias fraquezas. (Funakoshi, 1994, p. 121)

Logo no início do recorte acima há um trecho que merece destaque: "uma das razões que os levaram a escolher o Karate-do é a possibilidade de se tornarem fortes". Após tanto tratarmos dos aspectos morais e espirituais enaltecidos por Funakoshi, perde-se de vista motivos mais primários, simples que são os que, comumente, levam as pessoas a buscarem a prática do karate. Esses na realidade são fundamentais para a permanência na busca do desenvolvimento, pois "para que se possa esquecer de si mesmo durante o processo de realização formal, é preciso que a prática de tal arte seja atraente" (Herrigel, 1995, p. 48).

O conhecimento da fraqueza, da dificuldade, da falha seria parte do auto-conhecimento e o início da possibilidade de transformação. Isso não significa que toda a falha possa ser corrigida e toda fraqueza fortalecida. $\mathrm{O}$ fato de se ter consciência delas, porém, é tido como metade da vitória. $\mathrm{O}$ trecho indica também o método de ensino do zen, a compreensão é difícil, mas o momento de compreender chegará a cada um ao seu tempo e o Mestre não se adianta aos limites pessoais. Funakoshi parece não estar tratando de coisas diferentes quando fala de tornarse fraco e de tornar-se humilde. Tornar-se fraco seria suplantar o orgulho e a intenção orgulhosa que não permitiriam a percepção da realidade sem as distorções que somos capazes de provocar motivados por tais elementos. Nesse sentido tem-se que somente quem pôde suplantá-los, tornando-se 'fraco', tem a clara perspectiva da realidade e pode ter coragem verdadeira. Afinal a coragem voltada a uma realidade ilusória não pode ser considerada verdadeira pois facilmente vem abaixo. Captar a realidade como tal depende da suplantação desses elementos de distorção - dentre eles o medo da morte. Esses elementos nos são caros e por isso exigem grande esforço para superá-los:

O verdadeiro karate-do é um esforço interior para disciplinar a mente, desenvolvendo uma verdadeira consciência que permita, ao indivíduo, enfrentar o mundo mais dentro da realidade, desenvolvendo-se externamente e, ao mesmo tempo, adquirindo a força que lhe permita enfrentar um animal selvagem. Portanto, no karate-do, espírito e técnica devem ser uma coisa só. (Funakoshi, citado em Sasaki, 1995, p. 88)

Psicologia: Reflexão e Crítica, 2003, 16(2), pp. 379-388 
Essa realidade que se pretende apreender depende de uma vivência menos distorcida de si próprio: “O zen deseja atacar tempestuosamente esta cidadela de águas turvas e mostrar que nós, na realidade, vivemos psicologicamente e biologicamente - nunca logicamente" (Suzuki, 1992, p. 86).

Enfrentar a luta, enfrentar o mundo dentro da realidade, notando-se que o preparo físico e mental é imprescindível à capacidade de nela influir - essa é a mensagem.

Todo o processo de desenvolvimento espiritual proposto no karate-do sob a ótica do zen-budismo, faria com que, por fim, o conhecimento antes dado de fora para dentro, agora faça parte intrínseca do homem:

A compreensão da arte, o domínio da técnica e o aprimoramento das características de coragem, cortesia, integridade e autocontrole transformam-se na luz interior que vai guiar o praticante de karate em sua vida diária. Mas isso requer, pelo menos, dez a vinte anos de prática assídua e, se possível, toda uma existência devotada ao estudo do karate. (Funakoshi, citado em Sasaki, 1995, pp. 104-105)

\section{Conclusão}

Nas idéias de Gichin Funakoshi sobre a prática como forma de educar, está a concepção de que a aprendizagem e o desenvolvimento dependem não só do intelecto (é importante destacar a relação de equilíbrio mente/corpo), mas da prática assídua e da própria experiência mental e física, incluindo-se aí a agonia proveniente dos treinamentos. Nos resultados foram expostos os conceitos de desenvolvimento que são baseados intrinsecamente no zen-budismo. Verificou-se também que, de acordo com o zen-budismo, o desenvolvimento espiritual dispensaria atribuições morais, pois essa natureza de valores surgiria naturalmente como decorrência do crescimento interno. Nesse sentido não deveríamos tomar a intensa recorrência à moralidade por parte de Funakoshi como contraditória? A educação de Funakoshi foi baseada principalmente no confucionismo - que é uma doutrina moral - portanto nada mais natural esperar-se que a moralidade fosse centro de seu ensinamento. De acordo com Sasaki (1995), Funakoshi procurou um mosteiro zen-budista a fim de dar este fundamento à prática do karate. Desse modo, a especificidade do zen no karate de Funakoshi parece ser posterior à do confucionismo. Apesar disso, esse não é o único nem o principal motivo da ênfase na moralidade ao invés da ênfase no desenvolvimento espiritual, que naturalmente levaria à moralidade. A própria luta e, muitas vezes, as intenções de se fazer uso do karate em lutas, parecem ser causas que explicariam a exigência de um controle mais urgente - o inculcamento de regras morais - do que o longo processo espiritual que levaria à geração espontânea de moralidade. Assim, o zen fica como fundamento para o crescimento interior, não baseado na moral e não podendo substituí-la a tempo de evitar possíveis maus usos do karate. A moralidade confuciana substitui as rígidas regras dos mosteiros zen budistas, que servem como forma de contenção pré-iluminação de possíveis atos inadequados que pudessem vir a ser realizados em nome do zen. Dessa maneira, poder-se-ia supor que, após dezenas de anos de experiência, Funakoshi tenha reconhecido que a moralidade, pura e simplesmente, fosse um paliativo indispensável para favorecer o longo processo no qual esta surgiria como fruto do desenvolvimento espiritual almejado por um karate tido como modo de vida. O Zen está ainda conceituando aprendizagem, atuações didáticas e experiências internas.

Considera-se também que para apreender-se a realidade tal qual ela é verdadeiramente, seria preciso que houvesse um desprendimento mental. O karate poderia, através do treinamento, desenvolver a correta apreensão da realidade. Essa dita liberdade poderia ser expressa na luta e se daria em dois âmbitos, o do pensamento e o da emoção. Experimentar em treinamento dificuldades físicas e agonia enfrentando-as e superando-as, favoreceria enfrentar semelhantes experiências com mais facilidade em ocasiões diferentes. Esse é o modelo mais demonstrativo do valor de manter-se preparado e em constante aperfeiçoamento. $\mathrm{O}$ treino exaustivo e as lutas emocionalmente perturbadoras servem de experiência para se colocar em prática um modelo de como lidar na vida com essas mesmas situações. A perturbação emocional não deve ocorrer, deve-se manter um equilíbrio mental a fim de que as emoções, não vindo a ser nem extremamente positivas nem extremamente negativas, não chegassem a interferir na ação e na percepção da realidade. O pensamento preso a preconceitos - derrotistas, por exemplo - também é um elemento capaz de interferir na percepção da realidade externa. $O$ pensamento e a emoção deveriam estar em acordo com a realidade, de forma a não interferir em sua apreensão, sendo o controle sobre esses dois elementos a garantia de adequação ao real mesmo quando se trata com o desconhecido. Assim, em última instância é a aceitação da morte (que poderíamos chamar no Ocidente de o maior desconhecido) sem medo, tendo-a como continuidade não dualística da vida, o mais importante passo para uma vida mentalmente desprendida. Após superado este medo, qualquer outro apego a valores torna-se pequeno e superável, qualquer ação torna-se fácil pois a emoção paralisante foi superada. 


\section{Referências}

Aoki, E. (1994). Japan: Profile of a nation. Tokyo, New York, London: Kodansha International.

Doeblin, A. (1940). O pensamento vivo de Confúcio (C. Lacerda, Trad.). São Paulo: Livraria Martins.

Funakoshi, G. (1994). Karate-Dô: O meu modo de vida (E. L. Calloni, Trad.). São Paulo: Cultrix. (Original publicado em 1975)

Funakoshi, G. (1998). Karate-Do Nyumon: Texto introdutório do Mestre (E. L. Calloni, Trad.). São Paulo: Cultrix. (Original publicado em 1988)

Funakoshi, G. (1997). Karate-Dô Kyôhan: The master text (T. Oshima, Trad.). Tokyo, New York, London : Kodansha International. (Original publicado em 1973)

Herrigel, E. (1995). A arte cavalheiresca do arqueiro Zen (J. C. Ismael, Trad.). São Paulo: Pensamento. (Original publicado em 1975)

Massimi, M. (1998). A história das idéias psicológicas: Uma viagem no tempo rumo aos novos mundos. Em G. Romanelli \& Z. M. BiasoliAlves (Orgs.), Diálogos metodológicos sobre prática de pesquisa (pp. 11-30). Ribeirão Preto/SP: Legis Summa.

Massimi, M., Campos, R. H. \& Brozek, J. (1996). Historiografia da Psicologia: Métodos. Em R. H. Campos (Org.), História da Psicologia: Pesquisa, formação e ensino (pp. 29-56). Coletâneas da ANPEPP ( $\mathrm{n}^{\mathrm{O}}$. 15)/ São Paulo: EDUC/ANPEPP.
Musashi, M. (1996). O livro de cinco anéis (F. B. Ximenes, Trad.). Rio de Janeiro: Brasileira/Ediouro. (Original publicado em 1984)

Sasaki, Y. (1995). Karate-Dô. São Paulo: CEPEUSP.

Stevens, J. (1997). Les trois Maitres du Budo (P. Reymond, V. Melin \& T. Plée, Trads.). Noisy-sur-École: Budo Éditions, Les Éditions de l'Éveil.

Suzuki, D. T. (1992). Introdução ao Zen-Budismo (M. N. Azevedo, Trad.). São Paulo: Pensamento. (Original publicado em 1969)

Tzu, S. (1997). A arte da guerra (J. Sanz, Trad.). Rio de Janeiro: Record. (Original publicado em 1983)

Yamashiro, J. (1982). História dos Samurais. São Paulo: Hamburg.

Yamashiro, J. (1997). Japão passado e presente. São Paulo: Aliança Cultural Brasil-Japão.

Sobre os autores

Cristiano Roque Antunes Barreira é Doutorando no Programa de Pós-Graduação em Psicologia da Faculdade de Filosofia, Ciências e Letras de Ribeirão Preto da Universidade de São Paulo.

Marina Massimi é Doutora, é Professora associada da Faculdade de Filosofia, Ciências e Letras de Ribeirão Preto da Universidade de São Paulo. 